\title{
Incidence and risk factors for herpes zoster after adult liver transplantation
}

\author{
Wontae Kim, Sangjin Kim, Jongwook Oh, Young Jae Jeong, Jinsoo Rhu, Kyung Sik Kim, Jisoo Lee, \\ Gyu-Sung Choi, Jong Man Kim, Jae-Won Joh
}

Department of Surgery, Samsung Medical Center, Sungkyunkwan University School of Medicine, Seoul, Korea

\begin{abstract}
Purpose: Herpes zoster (HZ) is caused by reactivation of the varicella zoster virus, which occurs frequently in liver transplant recipients with impaired cellular immunity. The purpose of this study was to evaluate the incidence and risk factors for $\mathrm{HZ}$ after adult liver transplantation (LT).

Methods: In our institution, 993 patients underwent adult LT from January 1997 to December 2013. We retrospectively analyzed the incidence rate of $\mathrm{HZ}$ and risk factors for $\mathrm{HZ}$ after $\mathrm{LT}$.

Results: Of 993 LT recipients, 101 (10.2\%) were diagnosed with $\mathrm{HZ}$. The incidence of $\mathrm{HZ}$ at 1, 3, 5, and 10 years was $6.6 \%$, $9.1 \%, 10.0 \%$, and $11.9 \%$, respectively. Therefore, we observed that the incidence of HZ after LT was 16.3 per 1,000 personyears. Older age ( $\geq 50$ years) at LT and mycophenolate mofetil (MMF) exposure were independent risk factors of $\mathrm{HZ}$ infection after adult LT.

Conclusion: Patients older than 50 years or with MMF exposure are considered to be at high risk for HZ. Therefore, adult liver recipients with such factors should not be given strong immunosuppression treatments.

[Ann Surg Treat Res 2019;96(2):95-99]
\end{abstract}

Key Words: Herpes zoster, Incidence, Liver transplantation, Risk factors

\section{INTRODUCTION}

Varicella zoster virus (VZV) is a type of herpes virus that causes herpes zoster (HZ) by reactivation. $\mathrm{HZ}$ occurs more frequently in the elderly and in patients with underlying malignancies, impaired cellular immunity such as transplant patients, human immunodeficiency virus-infected, and other immunocompromised status [1]. The most common complication of $\mathrm{HZ}$ is postherpetic neuralgia, which is persistent pain that lasts more than 3 months after the skin rash heals [2].

Previous studies have determined that the incidence of $\mathrm{HZ}$ in solid organ transplant recipients is 10 to 100 fold higher than in the general population, which ranges from $1 \%$ to $12 \%$
[3,4]. Some reports have suggested that patients that receive mycophenolate mofetil (MMF) show higher $\mathrm{HZ}$ infection after liver transplantation (LT) as immunosuppressive treatment. Several studies have evaluated the incidence and risk factors of HZ after LT; however, there are currently no studies that have investigated the incidence and risk factors of $\mathrm{HZ}$ after $\mathrm{LT}$ in the Korean population.

The purpose of this study was to evaluate the incidence and risk factors of $\mathrm{HZ}$ after $\mathrm{LT}$ in the general Korean population.
Received July 12, 2018, Revised September 18, 2018, Accepted October 5, 2018

\section{Corresponding Author: Jong Man Kim}

Department of Surgery, Samsung Medical Center, Sungkyunkwan University School of Medicine, 81 Irwon-ro, Gangnam-gu, Seoul 06351, Korea

Tel: +82-2-3410-1719, Fax: +82-2-3410-0040

E-mail: yjongman21@gmail.com

ORCID code: https://orcid.org/0000-0002-1903-8354

\footnotetext{
Copyright (c) 2019, the Korean Surgical Society

(c) Annals of Surgical Treatment and Research is an Open Access Journal. All articles are distributed under the terms of the Creative Commons Attribution NonCommercial License (http://creativecommons.org/licenses/by-nc/4.0/) which permits unrestricted non-commercial use, distribution, and reproduction in any medium, provided the original work is properly cited.
} 


\section{METHODS}

\section{Patients}

Between January 1997 and December 2013, 1,191 adult (age $\geq 18$ years) patients underwent LT at Samsung Medical Center. These patients were retrospectively analyzed, and a total of 198 patients with the following conditions were excluded: death within 4 weeks after LT ( $n=62)$ or insufficient or no follow-up data $(n=136)$. Finally, 993 patients were included for analysis. A clinical diagnosis of $\mathrm{HZ}$ infection was determined by obvious skin lesions or by a dermatologist's exam.

$\mathrm{HZ}$ cases were identified through detailed chart review and a database search for any subject with the HZ-related disease classification code. In addition, we investigated clinical outcome variables, including age at transplantation, sex, cause of transplantation, model for end-stage liver disease (MELD) score, Child-Pugh classification, retransplant, immunosuppression before $\mathrm{HZ}$ development, acute rejection before $\mathrm{HZ}$ development, and steroid pulse therapy.

\section{Immunosuppression}

In our center, basiliximab (20 $\mathrm{mg})$ was used as an induction agent in all recipients during LT and on day 4 after LT. Patients were infused with prostaglandin E1, gabexate mesilate, and methylprednisolone. Maintenance immunosuppressive therapy consisted of corticosteroids, tacrolimus, and MMF. All transplant recipients were given $500 \mathrm{mg}$ of intravenous methylprednisolone during the anhepatic phase until postoperative day 2; this dosage was tapered to $60 \mathrm{mg}$ per day for a period of five days and then to $8 \mathrm{mg}$, twice per day, for $1 \mathrm{month}$ starting on postoperative day 8 . Corticosteroids were withdrawn at 3 months after transplantation. Tacrolimus treatment was initiated on postoperative day 3 , and the optimal blood level was adjusted to maintain a trough plasma concentration of 10 $\mathrm{ng} / \mathrm{mL}$ during the first month, which was then reduced to 5-8 $\mathrm{ng} / \mathrm{mL}$. Beginning on postoperative day 1,750 $\mathrm{mg}$ of MMF was administered twice per day.

\section{Statistical analysis}

Statistical analysis was performed using IBM SPSS Statistics ver. 23.0 (IBM Co., Armonk, NY, USA), a P-value $<0.05$ was considered statistically significant, and confidence intervals were set at the $95 \%$ level. Continuous variables are presented as mean \pm standard deviations and categorical variables are presented as the number of cases and percentage (\%). The Mann-Whitney U-test was used for continuous variables, and the chi-square test and Fisher exact test were used for categorical variables. The cumulative incidence of $\mathrm{HZ}$ was calculated using the Kaplan-Meier method, and survival curves were evaluated using the log-rank test. Only variables with a statistical P-value $<0.05$ in the univariate analysis were entered into the Cox regression model for multivariate analysis.

This study was approved by the Institutional Review Board of Samsung Medical Center (approval number: 2018-06-141) with approval of a waiver of informed consent.

\section{RESULTS}

\section{Patient characteristics}

Of 1,191 adult patients who underwent LT at Samsung Medical Center between January 1997 and December 2013. 993 were selected for analysis (Table 1). The median patient age was 52 years (range, 19-77 years). The causes of LT were hepatocellular carcinoma ( $n=466,46.9 \%$ ), HBV - or HCVassociated liver cirrhosis ( $\mathrm{n}=357,36.0 \%$ ), alcoholic cirrhosis ( $n=71,7.2 \%)$, acute liver failure $(n=35,3.5 \%)$, progressive intrahepatic cholestatic disease $(n=10,1.0 \%)$, and other causes $(\mathrm{n}=54,5.4 \%)$. Of 993 patients, $29(2.9 \%)$ underwent reransplantation. The median MELD score was 20 points, and 532 patients (53.6\%) had Child-Pugh class C. Among the calcineurin inhibitors (CNI), tacrolimus was used in 795 patients $(80.1 \%)$, and cyclosporine was used in 119 patients

Table 1. Patient characteristics

\begin{tabular}{lccc}
\hline \multicolumn{1}{c}{ Characteristic } & $\begin{array}{c}\mathrm{No} \mathrm{HZ} \\
(\mathrm{n}=892)\end{array}$ & $\begin{array}{c}\mathrm{HZ} \\
(\mathrm{n}=101)\end{array}$ & P-value \\
\hline Age at LT $\geq 50$ years & $609(68.3)$ & $79(78.2)$ & 0.040 \\
Male sex & $695(77.9)$ & $73(72.3)$ & 0.200 \\
MELD score & $20.4 \pm 10.8$ & $19.9 \pm 8.8$ & 0.582 \\
Child-Pugh classification & & & \\
A & $124(13.9)$ & $16(15.8)$ & \\
B & $296(33.2)$ & $25(24.8)$ & \\
C & $472(52.9)$ & $60(59.4)$ & 0.229 \\
Causes of LT & & & \\
Alcoholic cirrhosis & $66(7.4)$ & $5(5.0)$ & \\
HCC & $421(47.2)$ & $45(44.6)$ & \\
HBV or HCV cirrhosis & $316(35.4)$ & $41(40.6)$ & \\
ALF & $32(3.6)$ & $3(3.0)$ & \\
PBC or PSC & $9(1.0)$ & $1(1.0)$ & \\
$\quad$ Others & $48(5.4)$ & $6(5.9)$ & 0.886 \\
Retransplant & $25(2.8)$ & $4(4.0)$ & 0.527 \\
Use of tacrolimus & $708(79.4)$ & $87(86.1)$ & 0.107 \\
Use of cyclosporine & $108(12.1)$ & $11(10.9)$ & 0.721 \\
Use of MMF & $752(84.3)$ & $93(92.1)$ & 0.038 \\
Use of steroid & $211(23.7)$ & $23(22.8)$ & 0.843 \\
ACR (+) & $175(19.6)$ & $21(20.8)$ & 0.779 \\
Steroid pulse therapy & $150(16.8)$ & $16(15.8)$ & 0.804 \\
\hline
\end{tabular}

Values are presented as number $(\%)$ or mean \pm standard deviation.

$H Z$, herpes zoster; LT, liver transplantation; MELD, model for end-stage liver disease; HCC, hepatocellular carcinoma; ALF, acute liver failure; PBC, primary biliary cirrhosis; PSC, primary sclerosing cholangitis; MMF, mycophenolate mofetil; ACR, acute cellular rejection. 
(12.0\%). A total of 845 patients (85.1\%) were treated with MMF, and 234 patients $(23.6 \%)$ were treated with steroids. The median duration of MMF use before development of $\mathrm{HZ}$ was 137 days (range, 13-4,277 days). Acute cellular rejection was diagnosed in 196 patients (19.7\%), 166 of whom (84.7\%) were treated with IV steroid pulse therapy.

\section{$\mathrm{HZ}$ incidence}

The median follow-up time was 5.82 years (range, 0.04-18.83 years). A total of 101 patients (10.2\%) were diagnosed with $\mathrm{HZ}$ infection during the follow-up period after LT. The median time of $\mathrm{HZ}$ incidence after LT was 172 days (range, 13-4,277 days). Table 1 shows the clinical characteristics of patients that developed $\mathrm{HZ}$. The incidence of $\mathrm{HZ}$ at $1,3,5$, and 10 years was $6.6 \%, 9.1 \%, 10.0 \%$, and $11.9 \%$, respectively (Fig. 1). The incidence of $\mathrm{HZ}$ after LT was 16.3 per 1,000 person-years.

\section{$\mathrm{HZ}$ risk factors}

The mean age of patients with $\mathrm{HZ}$ was higher than that of patients without $\mathrm{HZ}(53.6 \pm 8.0$ years vs. $50.6 \pm 9.2$ years, $\mathrm{P}=$ 0.004). The proportion of MMF exposure in the patients with $\mathrm{HZ}$ was higher than in patients without $\mathrm{HZ}(92.1 \%$ vs. $84.3 \%, \mathrm{P}=$ 0.038 ). However, other characteristics were not significantly different between the 2 groups.

Univariate and multivariate analyses of factors associated with $\mathrm{HZ}$ infection are shown in Table 2. In univariate analysis, older age ( $\geq 50$ years) at $\mathrm{LT}(\mathrm{P}=0.042)$ and $\mathrm{MMF}$ exposure $(\mathrm{P}=0.038)$ were associated with a higher risk of $\mathrm{HZ}$ infection. In subsequent multivariate analysis, age ( $\geq 50$ years) at LT $(P=0.046)$ and MMF exposure $(\mathrm{P}=0.045)$ were independent risk factors of $\mathrm{HZ}$ infection after LT.

\section{DISCUSSION}

$\mathrm{HZ}$ is caused by reactivation of the varicella-zoster virus. This

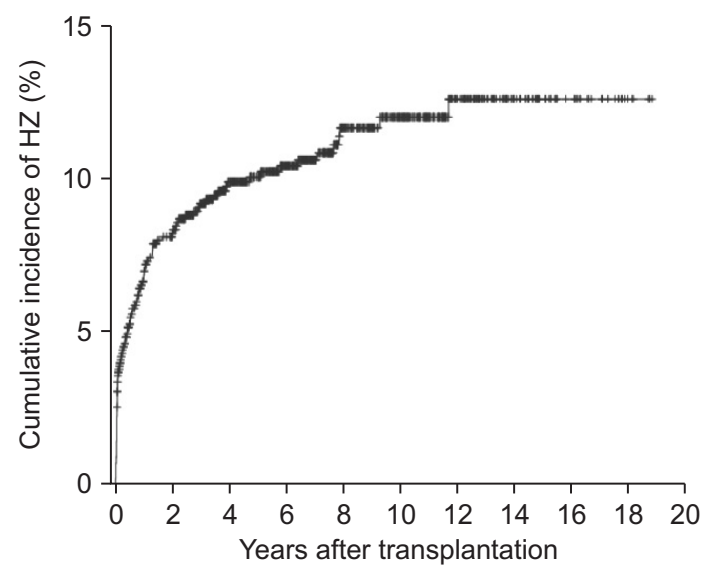

No. at risk $993807613480312222123 \quad 54 \quad 25 \quad 5$

Fig. 1. Cumulative incidence of herpes zoster $(\mathrm{Hz})$. virus can remain latent in the cranial nerve ganglia and dorsal root ganglia after primary infection (chickenpox) [5]. HZ and associated complications can be serious and painful. The annual incidence of $\mathrm{HZ}$ in the general population is $1.5-3.0$ cases per 1,000 persons [6]. Immunosuppression in LT may increase the incidence of $\mathrm{HZ}$. Aging and impaired cellular immunity, as seen in transplant patients, human immunodeficiency virus-infected patients, and other immunocompromised patients, have been suggested as risk factors $[4,7,8]$.

This study demonstrated that the incidence of $\mathrm{HZ}$ after LT is 16.3 per 1,000 person-years, and this result was similar to previously reported results $(17.83 / 1,000$ and $18.3 / 1,000$ personyears) $[4,8]$. This incidence is lower than in other solid-organtransplant (SOT) recipients. Pergam et al. [8] suggested that the liver is relatively resistant to rejection compared with other organs, so liver transplant recipients generally require less immunosuppression, and the incidence of $\mathrm{HZ}$ was lower than in lung and heart transplant recipients.

The calculated incidence in this study is much higher than in the general Korean population (10.4 per 1,000 person-years) [2]. These differences are highly associated with decreased immunity in SOT recipients who are vulnerable to infection due to chronic immunosuppression. According to other reports, the risk of $\mathrm{HZ}$ in SOT recipients is 2-10 fold higher than in the general population $[9,10]$. Previous studies reported a higher female $\mathrm{HZ}$ incidence in the general population, with a relative risk in the range of 1.2-1.47 [11]. Ko et al. [12] also reported that the only independent risk factor for $\mathrm{HZ}$ after kidney transplantation was female gender. In our study however, the

Table 2. Univariate and multivariate analyses of factors associated with herpes zoster

\begin{tabular}{lccc}
\hline \multicolumn{1}{c}{ Risk factor } & P-value & $\begin{array}{c}\text { Odds } \\
\text { ratio }\end{array}$ & $95 \% \mathrm{Cl}$ \\
\hline Univariate analysis & & & \\
Age at LT $\geq 50$ years & 0.042 & 1.669 & $1.019-2.732$ \\
MELD score $(\geq 25)$ & 0.854 & 0.961 & $0.628-1.469$ \\
Female sex & 0.191 & 1.362 & $0.857-2.165$ \\
Child-Pugh class C & 0.352 & 1.215 & $0.805-1.835$ \\
Retransplant & 0.515 & 1.430 & $0.488-4.195$ \\
Tacrolimus & 0.110 & 1.615 & $0.898-2.905$ \\
Cyclosporine & 0.721 & 0.887 & $0.460-1.712$ \\
MMF & 0.038 & 2.164 & $1.028-4.556$ \\
Steroid & 0.843 & 0.952 & $0.583-1.553$ \\
ACR & 0.779 & 1.076 & $0.647-1.788$ \\
Steroid pulse therapy & 0.804 & 0.931 & $0.531-1.634$ \\
Multivariate analysis & & & \\
Age at LT $\geq 50$ years & 0.046 & 1.655 & $1.010-2.712$ \\
MMF & 0.045 & 2.142 & $1.016-4.513$ \\
\hline
\end{tabular}

$\mathrm{Cl}$, confidence interval; MELD, model for end-stage liver disease; MMF, mycophenolate mofetil; ACR, acute cellular rejection; LT, liver transplantation. 
incidence rate was not higher in women than in men, with 16.34 per 1,000 person-years in women vs. 16.89 per 1,000 person-years in men $(P=0.209)$.

Some previous studies have demonstrated age and immunosuppressive therapy as risk factors for $\mathrm{HZ}$ after solid organ transplantation [4]. We evaluated that older age ( $\geq 50$ years) at LT $(P=0.046)$ and MMF exposure $(P=0.045)$ were independent risk factors of $\mathrm{HZ}$ infection after LT. However, other immunosuppressive agents such as CNI (tacrolimus, cyclosporine) and steroids were not significantly correlated with the incidence of HZ. MMF is widely used in combination with CNI for maintenance immunosuppression to reduce CNI induced toxicities [13]. MMF targets lymphocytes and blocks proliferation of $\mathrm{T}$ and $\mathrm{B}$ cells. Nucleotide synthesis in lymphocytes is interrupted by MMF, with depletion of intracellular pools of guanosine triphosphate [14]. The VZVspecific T-cell immunity is critical for preventing $\mathrm{HZ}$ after the primary VZV infection has resolved. A decrease in bloodcirculating VZV-specific T lymphocytes, resulting from immunosuppressive agents such as MMF, is associated with increased risk of VZV reactivation from latency [15]. However, there is no clear mechanism for $\mathrm{HZ}$ risk factors in transplant patients.

Age is an important factor that affects the incidence of $\mathrm{HZ}$. Cell-mediated immunity generally declines with age and may increase VZV reactivation due to a decrease in VZV-specific memory CD4 T cells [16]. The increased incidence of $\mathrm{HZ}$ with age was notable, and more than half of the cases were over 50 years old, with a peak age of 60-69 years in the general Korean population [2].

Acute cellular rejection was not different between patients treated with MMF and without MMF (20.4\% vs, 16.2\%; P = 0.243). In this study, we did not include data about renal dysfunction after LT that could be related with CNI toxicity. However, the proportion of cyclosporine use in the patients with MMF exposure was significantly lower than in the patients without MMF exposure (10.4\% vs. 20.9\%; P < 0.001). Probably, decreased cyclosporine use in patients treated with MMF may lower CNI toxicity [17].

There were several limitations to this study. First, it was a nonrandomized retrospective cohort study. Therefore, the patient information in our data may be incomplete. Second, the diagnoses of $\mathrm{HZ}$ were not all made by a dermatologist. Because of this, cases that were misdiagnosed or overdiagnosed could not be eliminated. Finally, we did not include additional data that could be associated with development of $\mathrm{HZ}$, including skin lesion distribution, clinical course, treatment, immunologic status variables such as splenectomy, other viral infections including cytomegalovirus, and blood level of immunosuppressant. However, in spite of these limitations, this is the first and largest study to investigate risk factors for $\mathrm{HZ}$ after LT and the incidence of $\mathrm{HZ}$ in the Korean population with a relatively long-term follow-up period.

In conclusion, our results demonstrate the incidence of $\mathrm{HZ}$ after LT and show that older age ( $\geq 50$ years) at LT and MMF exposure were independent risk factors of $\mathrm{HZ}$ infection after LT.

\section{CONFLICTS OF INTEREST}

No potential conflict of interest relevant to this article was reported.

\section{REFERENCES}

1. Levitsky J, Kalil A, Meza JL, Hurst GE, Freifeld A. Herpes zoster infection after liver transplantation: a case-control study. Liver Transpl 2005;11:320-5.

2. Kim YJ, Lee CN, Lim CY, Jeon WS, Park YM. Population-based study of the epidemiology of herpes zoster in Korea. J Korean Med Sci 2014;29:1706-10.

3. Herrero JI, Quiroga J, Sangro B, Pardo F, Rotellar F, Alvarez-Cienfuegos J, et al. Herpes zoster after liver transplantation: incidence, risk factors, and complications. Liver Transpl 2004;10:1140-3.

4. Hamaguchi Y, Mori A, Uemura T, Ogawa
K, Fujimoto Y, Okajima $\mathrm{H}$, et al. Incidence and risk factors for herpes zoster in patients undergoing liver transplantation. Transpl Infect Dis 2015;17:671-8.

5. Fishman JA. Overview: cytomegalovirus and the herpesviruses in transplantation. Am J Transplant 2013;13 Suppl 3:1-8.

6. Whitley RJ, Shukla S, Crooks RJ. The identification of risk factors associated with persistent pain following herpes zoster. J Infect Dis 1998;178 Suppl 1:S71-5.

7. Manuel O, Kumar D, Singer LG, Cobos I, Humar A. Incidence and clinical characteristics of herpes zoster after lung transplantation. J Heart Lung Transplant 2008;27:11-6.

8. Pergam SA, Forsberg CW, Boeckh MJ, Maynard C, Limaye AP, Wald A, et al. Herpes zoster incidence in a multicenter cohort of solid organ transplant recipients. Transpl Infect Dis 2011;13:15-23.

9. Koo S, Gagne LS, Lee P, Pratibhu PP, James LM, Givertz MM, et al. Incidence and risk factors for herpes zoster following heart transplantation. Transpl Infect Dis 2014; 16:17-25.

10. Miller GG, Dummer JS. Herpes simplex and varicella zoster viruses: forgotten but 
not gone. Am J Transplant 2007;7:741-7.

11. Gialloreti LE, Merito M, Pezzotti P, Naldi L, Gatti A, Beillat M, et al. Epidemiology and economic burden of herpes zoster and post-herpetic neuralgia in Italy: a retrospective, population-based study. BMC Infect Dis 2010;10:230.

12. Ko GB, Kim T, Kim SH, Choi SH, Kim YS, Woo JH, et al. Increased incidence of herpes zoster in the setting of cytomegalovirus preemptive therapy after kidney transplantation. Transpl Infect Dis 2013;15:416-23.
13. Klupp J, Pfitzmann R, Langrehr JM, Neuhaus P. Indications of mycophenolate mofetil in liver transplantation. Transplantation 2005;80(1 Suppl):S142-6.

14. Brennan DC, Aguado JM, Potena L, Jardine AG, Legendre C, Saemann MD, et al. Effect of maintenance immunosuppressive drugs on virus pathobiology: evidence and potential mechanisms. Rev Med Virol 2013;23:97-125.

15. Levin MJ, Smith JG, Kaufhold RM, Barber D, Hayward AR, Chan CY, et al. Decline in varicella-zoster virus (VZV)-specific cell-mediated immunity with increasing age and boosting with a high-dose VZV vaccine. J Infect Dis 2003;188:1336-44.

16. Yawn BP, Gilden D. The global epidemiology of herpes zoster. Neurology 2013;81: 928-30.

17. Schlitt HJ, Barkmann A, Boker KH, Schmidt HH, Emmanouilidis N, Rosenau $\mathrm{J}$, et al. Replacement of calcineurin inhibitors with mycophenolate mofetil in livertransplant patients with renal dysfunction: a randomised controlled study. Lancet 2001;357:587-91. 